\title{
Taking the Perfect Selfie: Investigating the Impact of Perspective on the Perception of Higher Cognitive Variables
}

\author{
Tobias M. Schneider ${ }^{1,2,3}$ and Claus-Christian Carbon ${ }^{1,2,3 *}$ \\ ${ }^{1}$ Department of General Psychology and Methodology, University of Bamberg, Bamberg, Germany, ${ }^{2}$ Bamberg Graduate \\ School of Affective and Cognitive Sciences, University of Bamberg, Bamberg, Germany, ${ }^{3}$ Research Group EPAEG \\ (Ergonomics, Psychological AEsthetics, Gestalt), Bamberg, Germany
}

Taking selfies is now becoming a standard human habit. However, as a social phenomenon, research is still in the fledgling stage and the scientific framework is sparse. Selfies allow us to share social information with others in a compact format. Furthermore, we are able to control important photographic and compositional aspects, such as perspective, which have a strong impact on the assessment of a face (e.g., demonstrated by the height-weight illusion, effects of gaze direction, faceism-index). In Study 1,

OPEN ACCESS

Edited by:

Nicola Bruno,

University of Parma, Italy

Reviewed by:

Egon L. Van Den Broek,

Utrecht University, Netherlands

Andrej Košir,

University of Ljubljana, Slovenia Annukka Kim Lindell,

La Trobe University, Australia

*Correspondence:

Claus-Christian Carbon ccc@uni-bamberg.de

Specialty section: This article was submitted to Human-Media Interaction, a section of the journal

Frontiers in Psychology

Received: 23 November 2016 Accepted: 26 May 2017 Published: 09 June 2017

Citation:

Schneider TM and Carbon C-C (2017) Taking the Perfect Selfie: Investigating the Impact of Perspective on the Perception of Higher Cognitive Variables. Front. Psychol. 8:971. doi: 10.3389/fpsyg.2017.00971 we focused on the impact of perspective (left/right hemiface, above/below vs. frontal presentation) on higher cognitive variables and let 172 participants rate the perceived attractiveness, helpfulness, sympathy, dominance, distinctiveness, and intelligence, plus important information on health issues (e.g., body weight), on the basis of 14 3D faces. We could show that lateral snapshots yielded higher ratings for attractiveness compared to the classical frontal view. However, this effect was more pronounced for left hemifaces and especially female faces. Compared to the frontal condition, $30^{\circ}$ right hemifaces were rated as more helpful, but only for female faces while faces viewed from above were perceived as significant less helpful. Direct comparison between left vs. right hemifaces revealed no effect. Relating to sympathy, we only found a significant effect for $30^{\circ}$ right male hemifaces, but only in comparison to the frontal condition. Furthermore, female $30^{\circ}$ right hemifaces were perceived as more intelligent. Relating to body weight, we replicated the so-called "height-weight illusion." Other variables remained unaffected. In Study 2, we investigated the impact of a typical selfie-style condition by presenting the respective faces from a lateral (left/right) and tilted (lower/higher) vantage point. Most importantly, depending on what persons wish to express with a selfie, a systematic change of perspective can strongly optimize their message; e.g., increasing their attractiveness by shooting from above left, and in contrast, decreasing their expressed helpfulness by shooting from below. We could further extent past findings relating to the heightweight illusion and showed that an additional rotation of the camera positively affected the perception of body weight (lower body weight). We discuss potential explanations for perspective-related effects, especially gender-related ones.

Keywords: selfie, viewing perspective, personality assessment, optimization, height-weight illusion, perspective, perception bias, face processing 


\section{INTRODUCTION}

Taking selfies is a well-known but still poorly investigated social phenomenon. In contrast to a classical portrait, it refers to a self-portrait picture taken by ourselves using e.g., the frontal camera of a smartphone and allows us to control important photographic and compositional aspects such as perspective, which has a strong impact on perceptual factors (e.g., variation of the assessed weight, the so-called "height-weight illusion", see Schneider et al., 2012). It is assumed that taking selfies has now become an important social phenomenon for expressing individual values and personality traits, showing off and sharing the current mood (see e.g., Sorokowska et al., 2016). Despite the high degree of relevance, there is only sparse research that has investigated whether selfies and related self-portraits serve as a valid predictor for personal traits (see e.g., Qiu et al., 2015; Teijeiro-Mosquera et al., 2015). More precisely, the "nature of selfies" is not well-investigated: It is suggested that viewing perspective/head rotation and picture details make a selfie different to a classical portrait (see e.g., Bruno and Bertamini, 2013; Bruno et al., 2014; Yeh and Lin, 2014). Other research relating to selfies has revealed that they can serve as valid cues for a respective person's personality traits (Qiu et al., 2015). More precisely, Guntuku et al. (2015) analyzed several visual cues (so-called "mid-level cues") relating to the selfietaker's personality (such as facial expression, photo location, Photoshop editing, amount of body visible etc.) and found that Agreeableness-in the sense of the Big-Five personality factors which are described as personality traits manifesting themselves in individual behavioral characteristics that are perceived as kind, sympathetic, cooperative, warm, and considerate-(see Thompson, 2008) was negatively correlated with camera height (agreeable individuals are more likely to take selfies from below). They further found that Conscientiousness-in the sense of the Big-Five which are described as personality traits manifesting themselves in individual behavioral characteristics such as being neat and systematic; also including such elements as carefulness, thoroughness, and deliberation-(see Thompson, 2008) was negatively correlated with private locations. Guntuku et al. (2015) argue that conscientious people do not like to expose their private space in the background. The authors further revealed that Neuroticism is negatively correlated with a duckface expression. However, a clear conclusion based on this resulting data pattern remains unclear. Evidence from research investigating whether faces provide valid predictions about personality related variables suggests that people seem to have high interrater consensus (in case of frontal facial presentations), but only when context information (e.g., expression, clothing, background, or speech) is visible. For example, Nestler et al. (2012) used standardized photographs and demonstrated that extraversion-in the sense of the Big-Five personality factors which are described as personality traits manifesting themselves in individual behavioral characteristics that are perceived as outgoing, talkative, and energetic behaviors-(see Thompson, 2008) is associated with facial attractiveness, while opennesswhat could be described by six dimensions or facets (of the BigFive personality factors) including active imagination (fantasy), aesthetic sensitivity, attentiveness to inner feelings, preference for variety, and intellectual curiosity (see Costa and McCrae, 1992) is associated with the volume of the lips, and conscientiousness is associated with facial femininity. In another study using full-body images Naumann et al. (2009) demonstrated that also for spontaneous poses and facial expression (in contrast to standardized photographs), observers made quite accurate predictions of the target's personality. Furthermore, also dynamic cues, such as clothing, provided valuable information for the predicted personality (see e.g., Penton-Voak et al., 2001; Qiu et al., 2015 for futher investigations).

For optimizing selfies in terms of what the depictions show in regard of higher cognitive variables, we might use specific perspectives-a method established for a very long time in the field of classical portrait photography. It was shown within a wide spectrum of research approaches that such higher cognitive variables can change the attitude and behavior toward the depicted person. For instance, facial attractiveness was revealed to positively affect gaze behavior (e.g., longer gaze duration, larger cone of gaze etc.) in human beings (see e.g., Maner et al., 2003, 2007; Leder et al., 2010, 2016; van Straaten et al., 2010; Baranowski et al., 2016). Research in the field of social psychology revealed that attractive individuals are perceived as more socially capable, popular, and competent (Dion et al., 1972; Eagly et al., 1991). They further earn more wages (Mobius and Rosenblat, 2006; Toledano, 2012), are even more likely to win political elections (Banducci et al., 2008; King and Leigh, 2009; Berggren et al., 2010), are sentenced more lenient by courts (Stewart, 1980), and are associated with a higher level of bodily health (Jones et al., 2001; Rhodes et al., 2001; Fink et al., 2006; Nedelec and Beaver, 2014).

However, past research identified perceived facial attractiveness, masculinity, and dominance as important cues to sexual fitness bodily health in male individuals, even if the manner how they interact remains inconsistent (see Penton-Voak et al., 2001 for a review). Masculine facial features (e.g., large jaws and prominent brows) in males are suggested to be testosterone dependent and therefore associated with greater immunocompetence, phenotypic and genetic quality, respectively (see e.g., Folstad and Karter, 1992; Thornhill and Grammer, 1999). On the one hand, Cunningham et al. (1990) as well as Grammer and Thornhill (1994) demonstrated that masculine facial features are preferred by female observers, while facial masculinity is highly related to the perceived dominance in male faces across female and male observers (see e.g., McArthur and Apatow, 1984; McArthur and Berry, 1987; Berry and Brownlow, 1989; Perrett et al., 1998). On the other hand, perceived dominance is highly correlated with associated muscle mass (Frederick and Haselton, 2007), as well as a higher level of testosterone (Swaddle and Reierson, 2002) in male individuals. However, scientific reports about direct effects of dominance on the perceived attractiveness are rather inconsistent, for example, positive effects are reported by e.g., Keating (1985), but see Perrett et al. (1998) for reported negative effects. With respect to viewing perspective and the perception of the associated dominance on the basis of faces, there is evidence that raising the head improves the perception of perceived dominance (e.g., 
Otta et al., 1994; Mignault and Chaudhuri, 2003; Chiao et al., 2008; Rule et al., 2012). Furthermore, Burke and Sulikowski (2010) revealed a strong relationship between upward postures and perceived masculinity. Results from studies investigating effects of facial lateralization (left hemiface which is from the owner's perspective the left side of the face vs. right hemiface which is from the owner's perspective the right side of the face) with chimaeric faces (combining one side of a face and mirroring it to the other side) revealed that the right hemiface is associated with higher ratings of attractiveness (see e.g., Zaidel et al., 1995; Burt and Perrett, 1997; but see Zaidel and Cohen, 2005 who only found effects for female faces). Following these results, we strongly expect that the showing the right cheek (right hemiface) positively affects the perceived attractiveness of a face. Furthermore, a face that is viewed from a lower vantage point should be perceived as more dominant.

Relating to female individuals, Jones (1995) revealed that faces that appear to be younger than the actual age (neotenous faces e.g., small lower jaw and nose, and large lips) are rated as more attractive by male raters across five populations. In a further experiment, Jones demonstrated that manipulation of facial features toward increased neoteny resulted in higher ratings of attractiveness. From an evolutionary perspective, preferring female youthful facial features by male individual was more adaptive since neoteny is highly associated with greater fertility, fecundity, phenotypic and genetic quality (see e.g., Thornhill and Gangestad, 1993; Perrett et al., 1998). Beside the fact that (primarily for female faces) the right hemiface is associated with higher perceived attractiveness, there is also evidence for lateralization effects on the perceived age. For example, Burt and Perrett (1997) revealed a right hemiface bias, hence the perceived age of the face is biased toward the right hemiface. Similarly, Hole and George (2011) suggested that holistic face processing (in the sense that facial parts are bound into a single "Gestalt," see Tanaka and Farah, 1993) plays an important role in age perception. Using the so-called "composite face effect" (assembling the top half of one face with the bottom half of a different face produces the impression of a "new" face) they asked participants to estimate the associated age of a composite face and found that participants' estimates were significantly biased toward the age of the bottom half of the face. Regarding direct changes of viewing perspective (or head posture), downward pitched heads appear to be younger and upward pitched heads appear to be older (Bruce et al., 1989). According to past research, we hypothesize a positive effect for the right hemiface on the perceived attractiveness also for female faces. Furthermore, with respect to the aforementioned relationship between perceived younger age and higher ratings of attractiveness in female faces, we cautiously assume that a downward pitched female face is associated with higher ratings of attractiveness.

There is also research on more "objective" variables relating to the actual health such as the body height and weight of the "selfied" person. It is scientifically recognized that body shape and mass is highly related to the associated health (e.g., Swami and Tovee, 2005, 2008; Furnham et al., 2006; Tovee et al., 2006) and faces also provide valid cues to body weight and health. For example, Coetzee et al. (2009), Coetzee et al.
(2010), as well as Tinlin et al. (2013) demonstrated that facial adiposity could be taken as a predictor of various health related variables, such as the associated immunological competence, cardiovascular function, frequency of respiratory infections, and ultimate mortality. Furthermore, facial adiposity is also highly correlated with the perceived attractiveness (Re and Rule, 2016). Viewing perspective, which is often used as a composition property in selfies, strongly affects the perception of these variables (Schneider et al., 2012, 2013). However, with respect to lateralization effects on the perceived health on the basis of faces, there is scientific disagreement (right side of the face see e.g., Reis and Zaidel, 2001; Kramer and Ward, 2011; Jones et al., 2012; but see Sitton et al., 2006 for the left side of the face).

In fact, many people use perspective as a powerful technique to enhance or optimize some further (non- health- and matingrelated) properties. Whether this is done implicitly or explicitly, it is clear that perspective is very differently employed in selfies and classical portraits (Bruno and Bertamini, 2013; Bruno et al., 2014). It is assumed that turning the face to the right (showing the left cheek: left hemiface) affects the perception of some emotions. More precisely, the left side of the face was rated as more emotionally expressive and emotions were perceived more intense (see e.g., Sackeim et al., 1978; Zaidel et al., 1995; Nicholls et al., 2002; Jones et al., 2012; Lindell, 2013a,b; Low and Lindell, 2016). This is widely in accordance with findings that the left cheek is overrepresented in classical portraits, see e.g., Bruno and Bertamini (2013) and McManus and Humphrey (1973); but also see contrasting research by Lindell (2016) who worked on specific cases of art history (i.e., Vincent Van Gogh's work). However, there are still some contradictions about the lateralization of perceptual aspects (e.g., the perception of highercognitive variables), for example, see Burt and Perrett (1997) or Jones et al. (2012). More precisely, there is some evidence for the asymmetrical facial organization of these variables. For example, as aforementioned, the right side of the face (right hemiface) affects the perception of attractiveness, sex and age, participants gaze at the right side of the face longer, whereas, the left side is perceived as more emotional and more expressive (see e.g., Sackeim et al., 1978; Burt and Perrett, 1997; Nicholls et al., 2002; Butler et al., 2005; Lindell, 2013a,b). Due to the importance of lateral effects and the non-consistent findings reported in the literature, we have made an overview of lateralization effects on a variety of face-relevant variables in Table 1 . That there are contradictory findings between face research and empirical findings from the domain of selfies might underline the hypothesis by Bruno et al. (2014) that selfies show a general and systematic deviation from known principles of photographic compositions.

The aim of the present study was to provide fundamental information what impact a change of perspective has on a variety of higher-order variables that are relevant for expressing personality and for mating. To the authors' knowledge, there is no systematic investigation of how viewing perspective affects the perception of higher cognitive variables (such as personality variables) on basis of faces, especially for more selfie-style conditions. Accordingly, we decided to use systematically varied full 3D models which have a clear advantage over typical analysis 
TABLE 1 | List of research which investigated the effect of hemiface (left vs. right) on the perception of attractiveness, emotional expression (posed and spontaneous), personality related variables, and health, showing that the results are quite far from consistent (emotional expression shows highly consistent results).

\begin{tabular}{|c|c|c|c|}
\hline Investigated variable & Study & $N$ & Lateralization effect ${ }^{\#}$ \\
\hline \multirow[t]{5}{*}{ Attractiveness } & Burt and Perrett, 1997 & 132 (73 female) & Right \\
\hline & Dunstan and Lindell, 2012 & 192 (129 female) & Right (o*/ơn.s. $)$ \\
\hline & Sitton et al., 2006 & 40 & Left \\
\hline & Zaidel and Cohen, 2005 & 27 (15 female)/21 (14 female) & No effect for attractive faces \\
\hline & Zaidel et al., 1995 & 26 (16 female) & Right $\left(q^{*} / 0^{\text {nn.s. }}\right)$ \\
\hline \multirow{5}{*}{ Emotional expression-posed } & Ekman et al., 1981 & 36 & Left: smiling \\
\hline & Indersmitten and Gur, 2003 & 38 (19 female) & Left: happiness, sadness, fear \\
\hline & Kowner, 1995 & 72 (36 female) & Left: smiling \\
\hline & Low and Lindell, 2016 & 90 (70 female) & Left: happiness \\
\hline & Zaidel et al., 1995 & 18 (9 female) & Left $\left(q^{*} / \sigma^{\star *}\right):$ smiling \\
\hline \multirow[t]{3}{*}{ Emotional expression-spontaneous } & Cacioppo and Petty, 1981 & 50 & Left: sadness \\
\hline & Dopson et al., 1984 & 34 (31 female) & Left: happy, sad \\
\hline & Indersmitten and Gur, 2003 & 38 (19 female) & Right: anger \\
\hline \multirow[t]{3}{*}{ Personality-related variables } & Jones et al., 2012 & 44 (25 female) & Right: general higher accuracy \\
\hline & Kramer and Ward, 2011 & 32 (25 female) & Right: general higher accuracy \\
\hline & Okubo et al., 2013 & 100 (50 female) & Left: trustworthiness (smiling faces) \\
\hline Health & Reis and Zaidel (2001) & 24 (12 female) & Left \\
\hline
\end{tabular}

\#Left, significant higher ratings for the left side of the face from owner's perspective (left hemiface).

Right, significant higher ratings for the right side of the face from the owner's perspective (right hemiface).

${ }^{*}$ Controlled for gender, effect was significant.

of selfie-photographs. The factor of is not confounded with other variables such as emotional expression, style, context etc. and therefore, this fundamental information can be easily transferred to statements about selfies. We investigated the impact of systematically manipulated viewing perspectives (see method section) on seven social- as well as health- and matingrelevant (so called higher cognitive) variables. First of all, we investigated attractiveness, dominance, intelligence, and body weight as important predictors to bodily health and fitness.

Secondly, past research in the field of social psychology has identified helpfulness or helping behavior as an important social variable. Helping behavior (or helpfulness) as a subcategory of prosocial behavior is intentional and it benefits another living being or group (Hogg and Vaughan, 2013). According to the question of the philosopher Turner (2005), whether altruistic and helpful behavior is an anomaly in human beings, there is a great debate across social psychologists (e.g., Campbell, 1975), sociobiologists (e.g., Wilson, 2000), and evolutionary social psychologists (e.g., Neuberg et al., 2010). The core question seems to be: is altruistic and helpful behavior a trait that has evolutionary survival value? From a raw biological view, altruistic and helpful behavior is associated with non-profitable enhancement of the reproductive fitness of another organism at one's own charge. Turner $(2005$, p. 317) further asked: “...how could natural selection ever smile upon organisms that sacrifice their own reproductive fitness for another's benefit?" However, this behavior is also empirically observable in animals which underlines the evolutionary importance of it: for example, some types of fishes enter the mouths of their hosts to remove parasites even at mortal danger (Stevens et al., 2005). From a more social psychological view, the apparent benefit of helpful behavior in social groups is well-documented in research (for example, the bystander intervention, whereby a person breaks out of the role of a bystander and helps another person in an emergency). Another finding is provided by Baumeister et al. (1988) who revealed a relationship between leadership and helping behavior. Leaders seem to have a generalized responsibility providing a buffer against the diffusion of responsibility.

Thirdly, sympathy as another important construct in social psychology. Empathy and sympathy are often used interchangeably. However, these terms have distinct meanings (Lishner et al., 2011). One definition of empathy is provided by 
Hogg and Vaughan (2013) who suggest that it is the ability to experiencing another person's emotions, thoughts and mindset. In contrast, sympathy is defined as a feeling of caring about someone else's trouble, sorrow or misfortune, but not necessarily the feeling of sharing the same feelings of another person. It could further be understood as a state of sharing the same interests, attitudes, goals etc. with another person. With respect to mating-related behavior (such as mating choice), research revealed sympathy as an important variable. In accordance with the so-called "homogamy hypothesis", people tend to seek for partners with similar hobbies, habits, interests, attitudes (e.g., religiosity) and mindsets (e.g., Hahn and Blass, 1997; Watson et al., 2004; Luo and Klohnen, 2005; Perry, 2015).

Distinctiveness. Carbon et al. (2010) pointed out that this term is somewhat ambiguously defined in research. Following the definition of Wickham and Morris (2003), distinctiveness can "traditionally" mean "standing out from a crowd" or, alternatively, "deviating from the average face" (so-called "deviation"). In the present paper, we used the traditional definition from face research with distinctiveness as an assessment of the salience of a face standing out of a crowd (of other faces). With respect to research in the field of perceived attractiveness and mating behavior, there is some evidence that symmetry, but also averageness could be taken as a predictor to bodily health (see e.g., Thornhill and Gangestad, 1993; Grammer and Thornhill, 1994; Shackelford and Larsen, 1997; Jones et al., 2001; Penton-Voak et al., 2001; Rhodes et al., 2001; Zaidel and Cohen, 2005; Fink et al., 2006). According to Valentine's (1991) so-called Multidimensional Face Space Model, typical faces (e.g., high level of averageness) are densely located near the centroid of this face space, hence these faces are highly similar; whereas distinctive faces are less densely clustered (Valentine, 1991; Newell et al., 1999). Thus, potential effects of rarely changes in viewing perspective on the perceived distinctiveness could be applied to selfie-related techniques.

The finding of evidence that viewing perspective has a great impact could lead to a better understanding of how a selfie should be taken and how we perceive a given face.

\section{STUDY 1}

\section{Methods}

Study 1 was conducted as an initial study where we wanted to find out which conditions were interesting in particular. Accordingly, we targeted to reveal even small effects. We further stressed the detection of effects against testing null-effects (focusing on $\alpha$ and not $\beta$ ). For the initial study, we had no knowledge of how strong our target variables (e.g., attractiveness and sympathy) correlated. Accordingly, we set all the pre-defined correlations to relatively weak intercorrelations. With an $\alpha$-level of 0.05 , a power of 0.80 and an effect size to be able to detect $f=0.10$ we obtained a minimum total sample size of 161 .

\section{Participants}

One Hundred and seventy two observers participated in the online based study (134 female; $M=25.2$ years, $S D=8.3$, range 18-61 years) on voluntary basis. Data were collected using the online survey tool "SoSci Survey" (Leiner, 2014). Most of the recruited participants were students of the University of Bamberg and gained course credit to fulfill course requirements. All other participants were recruited by online announcements (e.g., Facebook groups). All participants were naïve to the aim of the study and were not familiar with the presented faces.

\section{Materials}

In order to ascertain the precise orientation of a face with respect to the vantage point of the camera, we selected $3 \mathrm{D}$ face scans (Di3D-technology) of 14 human models (7 female, aged $M=25.0$ years, $S D=3.3$, range 20-31 years). We aligned these models with respect to a virtual camera and created $2 \mathrm{D}$ images of the faces corresponding to a camera position aligned with the inter-ocular point and perpendicular to the vertical axis of the face. We then rendered the image from seven camera perspectives (see Table 2) using Autodesk $3 \mathrm{ds}^{\mathrm{TM}}$ Max 2017 (note: the perspectives were all defined in terms of the face owner's view): above $30^{\circ}$ ("from above," which is equivalent to a camera raised and tilted by $30^{\circ}$ ), below $30^{\circ}$ ("from below," which is equivalent to a camera lowered and tilted by $30^{\circ}$ ), $15^{\circ}$ left (rotated, which is equivalent to a camera located $15^{\circ}$ to the left side of the face: we refer to this manipulation as left hemiface $15^{\circ}$ ), $30^{\circ}$ left (rotated, which is equivalent to a camera located $30^{\circ}$ to the left side of the face: we refer to this manipulation as left hemiface $30^{\circ}$ ), $15^{\circ}$ right (rotated, which is equivalent to a camera located $15^{\circ}$ to the right side of the face: we refer to this manipulation as right hemiface $15^{\circ}$ ), $30^{\circ}$ right (rotated, which is equivalent to a camera located $30^{\circ}$ to the right side of the face: we refer to this manipulation as right hemiface $30^{\circ}$ ), and $0^{\circ}$ (frontal view, which is equivalent to a frontal snapshot). The use of these seven perspectives was inspired by a study of Schneider et al. (2012) who only used gradations of $30^{\circ}$ which we extended by using more finely graduated levels of $15^{\circ}$ levels $\left(0^{\circ}, 15^{\circ}, 30^{\circ}\right)$. We refer to this manipulation as viewing perspective in the following. Please see example stimulus with the respective manipulation in Table 2.

\section{Procedure}

The study had two factors: model gender (gender of the shown face) and viewing perspective, with the dependent variable (rating of personality variables: attractiveness, helpfulness, sympathy, dominance, distinctiveness, intelligence, and the associated body weight) as the subordinate orders. Factor levels were blocked and their sequences were counterbalanced across participants. This resulted in 2 [gender of model] $\times 7$ [viewing perspective] $\times 7$ [personality dimensions] $=98$ trials. Each picture was presented in color on a black background and was standardized to a size of $600 \times 450$ pixels. Due to the fact that the study ran online, the actual size on the display could not be fully controlled. However, we asked the participants to avoid the use of a mobile device (such as mobile phones and tablets). Furthermore, we kindly asked the participants to use the full screen mode of their browser to reduce destructing visual cues.

For each stimulus, participants provided a rating (on a 7 point Likert scale) or body weight judgment (in kilograms) based on their individual, subjective and spontaneous impression, respectively (by presenting an initial sentence like e.g., "I perceive the shown face as..."). The scale ranged from "less" to "very" 


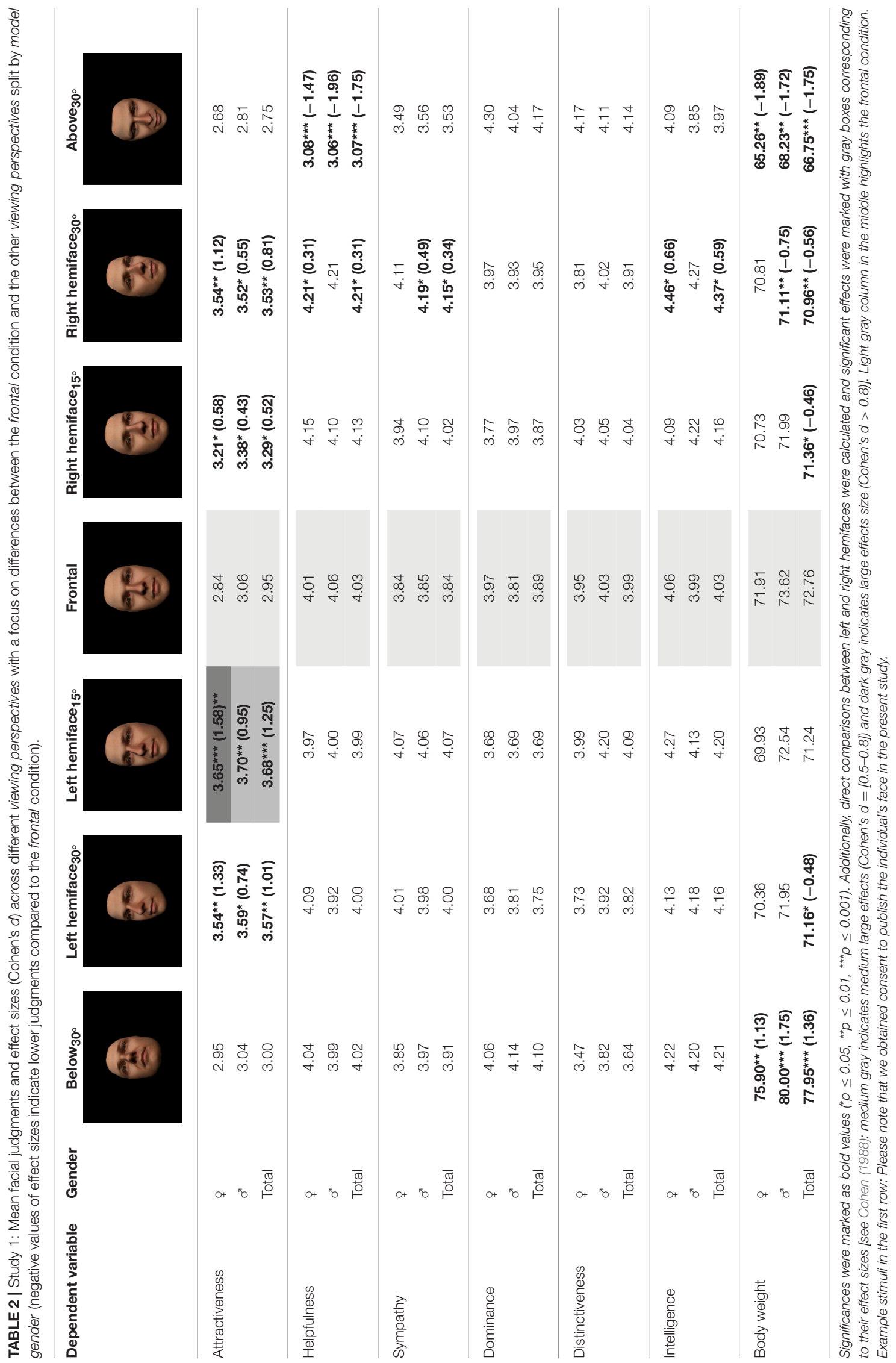


(e.g., "attractive"). For the variable distinctiveness, we additionally referred to the aforementioned definition: "a distinct face/person is remarkable standing out from a crowd of other faces/persons." With respect to the perceived body weight, the initial sentence was "Please judge the perceived body weight of the shown person in kilograms (in whole numbers)." Each trial started with a fixation cross followed by a blank screen and the target face until a response on the keyboard was made. The whole procedure lasted $\sim 15$ min.

\section{Results}

One of the main goals of this study was to understand the nature of selfies in contrast to conventional frontal portraits, such as current passport photos in the European Union. Accordingly, analyses focused on potential differences between the frontal condition and the other viewing perspectives. Data were analyzed with a two-factorial repeated-measures analysis of variance (rmANOVA) with the within-subject factor viewing perspective and the between-subject factor model gender. An univariate approach with Huynh-Feldt correction (Huynh and Feldt, 1976) for the degrees of freedom (df) was used (correction factor $\varepsilon$ ), which should be applied if $\varepsilon$ is $>0.75$ (Girden, 1992). Furthermore, it shows good control of the Type I error rate (Oberfeld and Franke, 2013). The original value of the $d f$ is reported. Partial $\eta^{2}\left(\eta_{p}^{2}\right)$ is reported as a measure of association strength. An $\alpha$-level of 0.05 was used for all analyses reported in this paper and all reported $p$-values are two-tailed. Pairwise comparisons and respective Cohen's $d$ were additionally calculated (see Table 2). Further analyses were conducted with a focus on the simple main effects. All assumptions of a repeated measurement ANOVA were sufficiently fulfilled: independence of observations, normality of distribution of residuals as well as the homoscedasticity across and within all groups. All analyses were conducted by using RStudio (ver. 0.99.903) for Mac.

Regarding the attractiveness ratings, we found a significant main effect of viewing perspective, $F_{(6,72)}=19.80, p<$ $0.0001, \eta_{p}{ }^{2}=0.62, \varepsilon=0.91$. In comparison to frontal snapshots $\left(M_{\text {frontal }}=2.95, S D_{\text {frontal }}=0.73\right)$, further analyses revealed that sided snapshots were rated as significantly more attractive. However, this effect was more pronounced for snapshots of the left hemiface compared to the right hemiface, but only for the $15^{\circ}$ left condition (direct comparison: $M_{15^{\circ} \text { left }}=3.68, S D_{15^{\circ} \text { left }}=0.38$ vs. $M_{15^{\circ} \text { right }}=3.29$, $\left.S D_{15^{\circ} \text { right }}=0.60 ; d=0.77\right)$. Although the left hemiface affected both genders, the effect was more pronounced for female faces (direct comparison: $M_{15^{\circ} \text { leftfemalefaces }=}$ $3.65, S D_{15^{\circ} \text { leftfemalefaces }}=0.35$ vs. $M_{15^{\circ} \text { rightfemalefaces }}=3.21$, $S D_{15^{\circ} \text { rightfemalefaces }}=0.62 ; d=0.89$ and $M_{15^{\circ} \text { leftmalefaces }}=$ 3.70, $S D_{15^{\circ} \text { leftmalefaces }}=0.43$ vs. $M_{15^{\circ} \text { rightmalefaces }}=3.38$, $\left.S D_{15^{\circ} \text { rightmalefaces }}=0.62 ; d=0.60\right)$. So, on average, showing the left cheek seems to be slightly more appealing, see Table 2.

Analyses for helpfulness revealed a significant main effect of viewing perspective, $F_{(6,72)}=29.53, p<0.0001, \eta_{p}{ }^{2}=0.711, \varepsilon=$ 1.00. Interestingly, in comparison to frontal snapshots $\left(M_{\text {frontal }}=\right.$ 4.03, $S D_{\text {frontal }}=0.64$ ), pairwise comparison revealed that faces photographed from a higher viewing perspective $\left(\right.$ above $\left._{30^{\circ}}\right)$ were rated as significantly less helpful, $\left(M_{\text {above } 30^{\circ}}=3.07, S D_{\text {above } 30^{\circ}}\right.$ $=0.44, d=-1.75$ ) across female and male faces, suggesting a body height dependent effect on the perception of helpfulness (see Table 2). For snapshots of the right hemiface $30^{\circ}$ we additionally found a small effect for only female faces $\left(M_{30^{\circ}}\right.$ right $=4.21$, $S D_{30^{\circ} \text { right }}=0.60, d=0.31$ ), see Table 2. However, direct comparisons of left vs. right hemifaces revealed no effect. Further analyses for the variable sympathy revealed a main effect of viewing perspective, $F_{(6,72)}=5.70, p<0.0001, \eta_{p}^{2}=0.322, \varepsilon$ $=0.87$. More specifically, we found a small effect for snapshots of the right hemiface $30^{\circ}\left(M_{30^{\circ} \text { right }}=4.15, S D_{30^{\circ} \text { right }}=0.77, d\right.$ $=0.40)$, see Table 2 . This effect was slightly more pronounced in male faces $\left(M_{30^{\circ}}\right.$ right $\left.=4.19, S D_{30^{\circ} \text { right }}=0.63, d=0.49\right)$. Again, direct comparisons of left vs. right hemifaces revealed no effect. Analyses for the variable intelligence revealed a small but significant main effect of viewing perspective, $F_{(6,72)}=2.39, p=$ $0.041, \eta_{p}{ }^{2}=0.166, \varepsilon=0.94$. In comparison to frontal snapshots $\left(M_{\text {frontal }}=4.03, S D_{\text {frontal }}=0.72\right)$, analyses revealed that the right hemiface $_{30^{\circ}}\left(M_{30^{\circ} \text { right }}=4.37, S D_{30^{\circ} \text { right }}=0.40, d=0.59\right)$ was rated as slightly more intelligent. Direct comparisons of left vs. right hemifaces revealed no effect.

Regarding the body weight judgments, we found a strong effect of viewing perspective, $F_{(6,72)}=31.10, p<0.0001, \eta_{p}{ }^{2}=$ $0.722, \varepsilon=0.95$, replicating the results reported by Schneider et al. (2012). In comparison to the frontal condition $\left(M_{\text {frontal }}=\right.$ $\left.71.91, S D_{\text {frontal }}=3.41\right)$, the associated body weight for faces photographed from a lower perspective $\left(M_{\text {below } 30^{\circ}}=77.95\right.$, $S D_{\text {below } 30^{\circ}}=4.10, d=1.36$ ) was rated as significantly higher than for faces photographed from a higher perspective $\left(M_{\text {above } 30^{\circ}}=\right.$ 66.75, $S D_{\text {above } 30^{\circ}}=3.37, d=-1.75$ ), see Table 2. We further found that snapshots of the right hemiface produced slightly lower body weight judgments $\left(M_{15^{\circ} \text { right }}=71.36, S D_{15^{\circ} \text { right }}=\right.$ $2.60, d=-0.46$ and $M_{30^{\circ} \text { right }}=70.96, S D_{30^{\circ} \text { right }}=2.89$, $d=-0.56$ ). Furthermore, left cheek views (showing the left hemiface) also produced significantly lower associated body weight assessments $\left(M_{30^{\circ} \text { left }}=71.16, S D_{30^{\circ} \text { left }}=3.11, d=\right.$ $-0.48)$. Other viewing perspectives had no effect on the associated body weight. We did not find any effects for the variables dominance or distinctiveness.

\section{Discussion}

The main goal of Study 1 was to investigate the potential effects of different perspectives on the perception of a given face, compared to classical frontal portrait photos. In Study 1, we let our participants rate person-related variables across different viewing perspectives on the basis of faces. We were able to show that in the case of attractiveness ratings, the perspective of the camera had a significant effect. This effect was especially positive for presentations of the left hemiface and more distinct for female faces (in contrast to male faces) what is in line with findings by Sitton et al. (2006), although others, e.g., Dunstan and Lindell (2012) did only found this effect for male faces. This optimization possibility is seemingly often used in the field when people take a selfie: Here, people tend to show a side bias (mostly showing the left cheek)-interestingly, the left hemiface has a significant effect on the perception of (positive) emotion (see McManus and Humphrey, 1973; Bruno and Bertamini, 2013; Lindell, 2013a,b; 
Low and Lindell, 2016). However, our results are also in some contrast to our initial hypothesis and also to other research: e.g., Burt and Perrett (1997) used chimeric faces and revealed that the right hemiface impacts attractiveness more than the left side. Other research e.g., Zaidel et al. (1995) as well as Dunstan and Lindell (2012) also revealed this right side effect but only for female faces. Furthermore, in our dataset the right hemiface also positively affected the perception of attractiveness although this effect was less pronounced. However, in these studies only frontal (partly chimeric) faces were used and stimuli were not rendered from 3D models. Dunstan and Lindell (2012), in contrast, used photographs of human models but with a visible torso and direct gaze toward the camera. In the present study, we decided to use fully rotated faces which were based on photogrammetry which allows the extracting of variable perspectives from one single face model, so that all instances show the very same face at one fixed moment in time. Similarly, Burke et al. (2007) and Schneider et al. (2012) suggested that depth information (which was highly available in our stimuli set) in particular contributes to differences in the perception of a face. In contrast to our hypothesis, we did not find any effects of elevating or lowering the camera, neither for male (lowering the camera) nor for female faces (elevating the camera). However, this is in line with recent research by Baranowski and Hecht (in press) who did not find such an effect in faces of (unknown) actors.

Regarding the variable helpfulness, we found a small but significant effect for right sided faces and a clear negative effect for faces shown from a higher vantage point, suggesting a heightdependent effect of viewing perspective on perceived helpfulness. Regarding the above $_{30^{\circ}}$ condition, which is equivalent to a taller person looking down on a smaller person, recent research revealed that taller persons are associated with greater leadership skills (Re et al., 2012, 2013). From this point of view, you may expect that smaller persons indeed rely on the helpfulness of the respective leader instead of being more helpful themselves. Accordingly, persons seen from above, such as typically smaller persons, might be assessed as less helpful_or even more precisely, as being potentially less helpful. Interestingly, we found such a perspective-relevant effect on helpfulness only with faces that are observed from above, but we failed to document an effect of higher helpfulness with faces observed from below. Furthermore, showing the right cheek (compared to the frontal condition) positively affects the perception of helpfulness especially for female faces. Beside the fact that this effect was rather small and not significantly larger for the left cheek condition, we could only speculate: similarly, we also found a significant and positive effect for the right hemiface on the perceived intelligence. Following the results of a recent study by Furnham and Cheng (2015), intelligence could be taken as a predictor for helpful behavior (as a facet of agreeableness). Accordingly, this may explain the similar pattern of helpfulness and intelligence. However, the effect of gender as well as the effect of rotation could not be sufficiently explained. A possible explanation for the right-side bias in the perception of intelligence is provided by findings that the right hemiface is associated with scientific, rational, academic and unemotional concepts (e.g., Nicholls et al., 1999; ten Cate, 2002; Lindell and Savill,
2010; Churches et al., 2012): e.g., in a study ten Cate (2002) presented pictures of professors of the eighteenth century and let participants rate how "scientific" they perceived the respective professor. Accordingly, participants rated the right cheek pictures as more scientific. This finding was further extended by Churches et al. (2012) who found that people intuitively show either the left or the right cheek, depending on what they want to express (scientists of core-sciences such was mathematics, engineering as well as chemistry show their right cheek, whereas scientists of human sciences such as psychology tended to show the left cheek).

With respect to the perceived sympathy, we found a significant and positive effect for right sided snapshots (showing the right cheek) especially for male faces (compared to the frontal condition). However, direct comparison of left vs. right hemifaces revealed no significant difference. Accordingly, our results might contrast past findings according to which the left hemiface is perceived as more emotional (see e.g., Sackeim et al., 1978; Zaidel et al., 1995; Nicholls et al., 2002; Jones et al., 2012; Lindell, 2013a,b; Low and Lindell, 2016). However, to the author's knowledge, there is no investigation on the perception of sympathy with respect to viewing perspective. Moreover, we assume that sympathy is only a single facet of the entire and complex construct of emotion. Thus, the pattern of our data leads to the speculation that it does not contradict past findings, since the perception of emotions is not homogenously unilaterally affected.

With respect to the perception of the associated dominance, past research revealed that raising the head improves the perception of it (e.g., Otta et al., 1994; Mignault and Chaudhuri, 2003; Chiao et al., 2008; Rule et al., 2012). Similarly, Burke and Sulikowski (2010) demonstrated a clear association between upward postures and perceived masculinity. Thus, we expected higher ratings for upward-pitched faces and lower ratings for downward-pitched faces, compared to the frontal condition. However, we did not find this effect in our sample. Moreover, there was not even any significant difference between upward vs. downward pitched faces. Calling our results into question, we suggest that cervical cues (e.g., the visibility of a neck) are essential for the perception of dominance (keep in mind that in the aforementioned studies, the neck was visible). Additionally, the human trapezius muscle (a large muscle that extends longitudinally from the occipital bone to the lower thoracic vertebrae and laterally to the spine of the shoulder blade) is more visible and especially the longus colli muscle (the long muscle of the neck) is in more tension in the case of raised heads. Most notably with male bodies, Frederick and Haselton (2007) demonstrated that perceived dominance is strongly dependent on the perceived muscle mass. Our set of stimuli was limited to neckless faces only. Accordingly, important cues to muscle mass and dominance were not accessible.

Considering past research, the effects that were mainly investigated were of viewpoint on recognition processes, relating to distinctiveness. It is suggested that distinctive faces are recognized better than ones that are more typical in their appearance (in the sense of Valentine, 1991 so-called Multidimensional Face Space Model): Typical faces are densely 
located near the centroid of this face space, hence there is a high potential for confusion; whereas distinctive faces are less densely clustered (e.g., Valentine, 1991; Newell et al., 1999). Regarding to our study, research revealed that in cases of unfamiliar face processing, changes due to (planar) rotation (i.e., a rotation called "roll") makes face recognition harder. In fact such a kind of rotation disrupts featural (e.g., Carbon and Leder, 2006; Stephan and Caine, 2007; Akselrod-Ballin and Ullman, 2008) as well as "configural processing" (e.g., Carbon and Leder, 2006; Favelle et al., 2011) and "holistic processing" (Tanaka and Farah, 1993; Leder and Carbon, 2005; Goffaux et al., 2009; but see Richler et al., 2011). In the present study we addressed the much-less-investigated case of faces rotated in terms of "yaw" and "pitch." Furthermore, relating to face recognition, research revealed an interaction between distinctiveness and viewing perspective. More specifically, it is suggested that the visibility of distinctive parts of a face varies across different viewing perspectives, hence recognition performance is dependent on the availability of these parts: distinctive facial features could be invisible in faces which are presented in profile (e.g., Valentin et al., 1999, 2001). However, direct potential effects of viewing perspective on distinctiveness have not yet been investigated. In our study, we could not find any effects of perspective on distinctiveness; probably the extent of utilized deviations from the frontal perspective was just not large enough to find any effects. This would be in accordance with previous research wherein robust face processing of configural aspects was documented up to a (planar) rotation of about $60^{\circ}$ from the frontal-upright orientation (Carbon et al., 2007).

In Study 1, we were able to replicate the so called "heightweight illusion" (first mentioned by Schneider et al., 2012) whereby faces seen from a higher viewing perspective are associated with a significantly lower body weight compared to faces seen from a lower viewing perspective. This advantage was slightly more pronounced in faces showing their right cheek (right hemiface). This finding is in accordance with research that revealed a preference for sided faces (e.g., Bruno and Bertamini, 2013; Yeh and Lin, 2014). Furthermore, it underlines the correlation between the perception of facial mass (and respective body weight), and perceived attractiveness (e.g., Tovee et al., 1998, 1999, 2006; Swami et al., 2006, 2010; Coetzee et al., 2009, 2010).

\section{STUDY 2}

Study 1 revealed that perspective has an impact on facial judgments, especially for body weight judgments (previews findings are reported by e.g., Schneider et al., 2012, 2013); other postulated effects were less pronounced or absent. However, the used viewing perspectives of Study 1 are sometimes found with selfies but some additional ones are even more typical of the selfie style (see e.g., Bruno et al., 2014). Just imagine that you are going to take a selfie on your next trip. It is unlikely that you will only rotate your mobile phone rigidly around one axis, but typically you will use a combination of such rotations. Accordingly, the aim of Study 2 was to examine the impact of typical perspectives of selfies on facial judgments.

For study 2, we focused on medium size effects as the study was framed in a more applied context expecting rather more noise and less signal. Accordingly, we adjusted our pre-sets in terms of effect size $(f=0.25)$ and power $(1-\beta=0.95)$, yielding a needed total sample size of 45 .

\section{Method \\ Participants}

Sixty-seven observers participated in the online-based study (52 female; $M=24.3$ years, $S D=3.6$, range $19-38$ years) on a voluntary basis. Data were collected using the online study tool "SoSci Survey" (Leiner, 2014). Method of recruiting participants was the same as in Study 1. All participants were naïve to the aim of the study; none of them participated in Study 1; they were not familiar to the presented faces.

\section{Materials}

The stimulus material of Study 2 was the same as in Study 1, with the difference that we changed the used viewing perspectives toward an even more selfie-esque style by combining tilted and rotated camera conditions (see Carbon, 2017). As a result, we got the following seven viewing perspectives (see Table 3):

- above $_{30^{\circ}}$, below ${ }_{30^{\circ}}$ (both, above $30^{\circ}$ and below $30^{\circ}$ as in Study 1),

- above $30^{\circ}$ left (combination: elevated/rotated, which is equivalent to a raised and tilted camera plus a camera located $30^{\circ}$

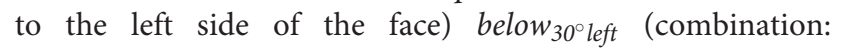
lowered/rotated, which is equivalent to a lowered and tilted camera plus a camera located $30^{\circ}$ to the left side of the face), above $30^{\circ}$ right (combination: elevated/rotated, which is equivalent to a raised and tilted camera plus a camera located

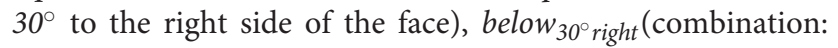
lowered/rotated, which is equivalent to a lowered and tilted camera plus a camera located $30^{\circ}$ to the right side of the face), and $0^{\circ}$ (frontal view, which is equivalent to a frontal snapshot).

\section{Procedure}

The procedure was the same as in Study 1.

\section{Results}

In Study 2 we focused again on the impact of different perspectives on several person-related variables, always with the frontal perspective as the base condition. To be able to optimally compare the results between both studies, we followed the same strategy of analyses (see details above).

Regarding the attractiveness ratings, we found a significant main effect of viewing perspective, $F_{(6,72)}=11.75, p<0.0001$, $\eta_{p}{ }^{2}=0.495, \varepsilon=1.00$. In comparison to frontal snapshots $\left(M_{\text {frontal }}=3.22, S D_{\text {frontal }}=0.90\right)$, analyses revealed that elevating and rotating the camera had a large positive effect on attractiveness $\left(M_{\text {above } 30^{\circ} \text { left }}=4.23, S D_{\text {above } 30^{\circ} \text { left }}=0.78, d\right.$ $=1.20$ and $M_{\text {above } 30^{\circ} \text { right }}=4.11, S D_{\text {above } 30^{\circ} \text { right }}=0.83, d=$ 1.02). In both cases (snapshots of the left and right hemiface), the effect was more pronounced for male faces $\left(M_{\text {above } 30^{\circ} \text { left }}=\right.$ 4.16, $S D_{\text {above } 30^{\circ} \text { left }}=0.96, d=1.77$ and $M_{\text {above } 30^{\circ} \text { right }}=$ 


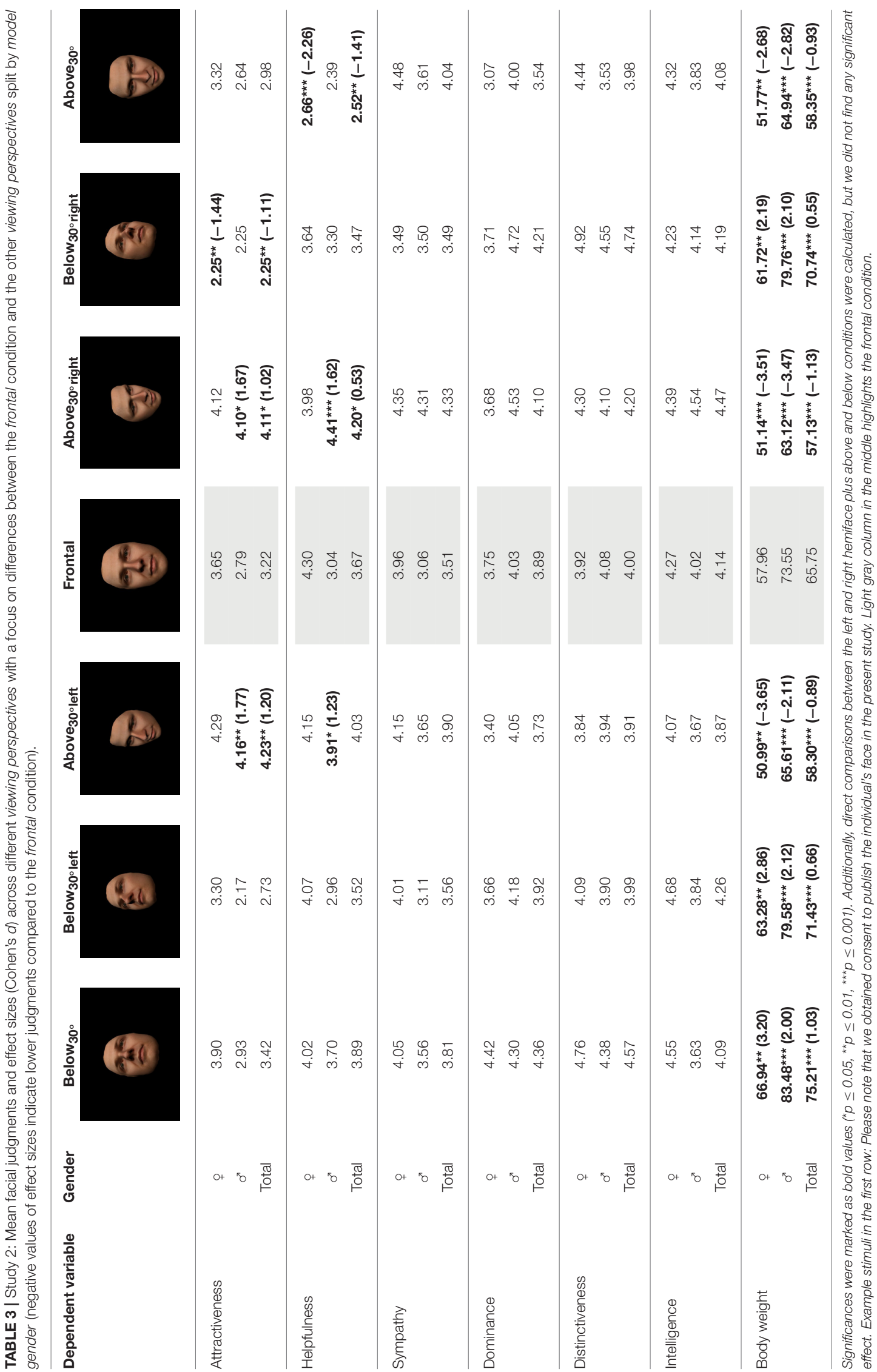


4.10, $\left.S D_{\text {above } 30^{\circ} \text { right }}=0.97, d=1.67\right)$. In contrast, lowering and rotating the camera had a negative effect on attractiveness $\left(M_{\text {below } 30^{\circ} \text { right }}=2.25, S D_{\text {below } 30^{\circ} \text { right }}=0.86, d=-1.11\right)$. This effect was more pronounced for female faces $\left(M_{\text {below } 30^{\circ} \text { right }}=\right.$ 2.25, $S D_{\text {below } 30^{\circ} \text { right }}=0.95, d=-1.44$ ), see Table 3.

Analyses for the variable helpfulness revealed a significant main effect of viewing perspective, $F_{(6,72)}=7.95, p<.0001$, $\eta_{p}{ }^{2}=0.398, \varepsilon=1.00$. Similarly to Study 1 , in comparison to frontal snapshots $\left(M_{\text {frontal }}=3.67, S D_{\text {frontal }}=1.08\right)$, faces photographed from a higher viewing perspective $\left(\right.$ above $\left.30^{\circ}\right)$ were rated as significantly less helpful $\left(M_{a b o v e 30^{\circ}}=2.52, S D_{a b o v e 30^{\circ}}=\right.$ $0.40, d=-1.41)$. This effect was particularly large for female faces $\left(M_{a b o v e 30^{\circ}}=2.66, S D_{-30^{\circ}}=0.45, d=-2.26\right)$, see Table 3 . Elevating the camera, however, did not have an effect. Specifically, for male faces, a combination of elevation and rotation of the camera $\left(\right.$ above $_{30^{\circ} \text { left }}$ and above $_{30^{\circ}}$ right $)$ led to significantly higher helpfulness ratings $\left(M_{\text {above } 30^{\circ} \text { left }}=3.91, S D_{\text {above } 30^{\circ} \text { left }}=0.55, d=\right.$ 1.23 and $M_{\text {above } 30^{\circ} \text { right }}=4.41, S D_{\text {above } 30^{\circ} \text { left }}=0.85, d=1.62$ ), suggesting an interaction of gender and viewing perspective. Regarding the variable sympathy, we found higher ratings for male faces which were photographed from a higher viewing perspective and rotated by $30_{\text {right }}^{\circ}$. However, this effect was not significant; see Table 3.

Regarding body weight judgments, we replicated the heightweight illusion (Schneider et al., 2012) which was also found in Study 1, see Table 3. Furthermore, compared to the frontal condition $\left(M_{\text {frontal }}=65.75, S D_{\text {frontal }}=8.65\right)$, lowering plus rotating the camera produced significantly higher body weight judgments $\left(M_{\text {below } 30^{\circ} \text { left }}=71.43, S D_{\text {below } 30^{\circ} \text { left }}=8.53, d=0.66\right.$ and $\left.M_{\text {below } 30^{\circ} \text { right }}=70.74, S D_{\text {below } 30^{\circ} \text { right }}=9.44, d=0.55\right)$. Interestingly these conditions (below ${ }_{30}{ }^{\circ}$ left and below $30^{\circ}$ right), were still slightly lower than the pure above $30^{\circ}$ condition without a horizontal rotation $\left(M_{\text {below3 } 30^{\circ}}=75.21, S D_{\text {below } 30^{\circ}}=9.71\right.$, $d_{\text {below } 30^{\circ} \text { left }}=-0.41$ and $d_{\text {below } 30^{\circ} \text { left }}=-0.47$ ). We could also detect that elevating and rotating the camera indeed produced significantly lower body weight judgments $\left(M_{\text {above } 30^{\circ} \text { left }}=58.30\right.$, $S D_{\text {above } 30^{\circ} \text { left }}=8.04, d=-0.89$ and $M_{\text {above } 30^{\circ} \text { right }}=57.13$, $\left.S D_{\text {above } 30^{\circ} \text { right }}=6.41, d=-1.13\right)$. Nevertheless, additional horizontal rotation of the camera did not significantly enhance the effect of height-weight illusion. In line with Study 1, we did not find any effects for the variables sympathy, dominance, distinctiveness, or intelligence.

\section{Discussion}

The aim of Study 2 was to examine whether more selfie-specific viewing perspectives have an even more pronounced effect on facial judgments. Accordingly, in Study 2, we let participants rate personality variables across different viewing perspectives on the basis of faces. In accordance with the findings of Study 1 , we could show that in case of attractiveness judgments were positively affected by horizontally rotating and elevating the camera. Similarly to Study 1, this effect was slightly (but not significantly) more pronounced for the left side of the face compared to the right side. We also reported larger effects for male faces compared to female faces. This suggests a clear preference for lateral and elevated snapshots. This conclusion is supported by findings that elevating the camera plus rotating the camera is generally preferred for taking selfies (Yeh and Lin, 2014; Kalayeh et al., 2015). An elevation within pure frontal depictions had no effect on attractiveness ratings at all what is in line with Study 1 and findings by Baranowski and Hecht (in press). However, there was a slight (but non-significant) decrease in perceived attractiveness. In the case of the below right condition (which is equivalent to a view from the right bottom) we found a decrease in perceived attractiveness, and this effect was even more pronounced for female faces. Burt and Perrett (1997) as well as Zaidel et al. (1995) argued that the right side of the owner's face positively affects the perception of facial attractiveness. However, this effect had not yet been investigated in combination with a classical selfie-style camera upward tilt. Similarly, it could be shown that facial cues can be taken as a valid predictor of body weight and this highly correlates with the perceived health and attractiveness (Coetzee et al., 2009, 2010).

Regarding the assessment of helpfulness in Study 2, we showed that elevating and rotating the camera had a significant and positive effect. Similarly to Study 1 , this effect was again slightly more pronounced in faces showing their right cheek $\left(\right.$ above $_{30^{\circ}}$ right). In contrast, we replicated the negative effect of Study 1 (a frontally elevated camera: the above $30^{\circ}$ condition is equivalent to a taller person looking downwards on a smaller person). At first sight this contradicts the finding of Study 1, where we argued the typical view of a taller person caused people to assess the viewed person as more helpful. The additional horizontal rotation eliminated this effect. We can only speculate at this point, but in the specific combination of tilting and rotating a camera might have induced a higher rating for helpfulness in Study 2 as this perspective reveals many details of the face and also looks quite realistic-the participants probably perceived a face from this perspective as much more of a real face than would have been the case with a flat picture of a face. The variable helpfulness might benefit from such a more holistic capture of a face to a greater extent than other variables.

Regarding the body weight judgments, we replicated the height-weight illusion that we also documented for Study 1 . From this point of view (Schneider et al., 2012), we expected and found generally higher body weight judgments for lower camera positions and generally lower body weight judgments for elevated camera positions. Surprisingly, in cases of lower camera positions (below ${ }_{30^{\circ} \text { left }}$ and below ${ }_{30}{ }^{\circ}$ right), we were able to show that a further camera rotation slightly reduced the effect of higher body weight judgments and this was significant compared to the below $w_{30}$ control condition. This suggests a strong positive rotation effect on perceived body weight, which is in accordance with the findings of Study 1. Similarly, we also found a slight but non-significant advantage in the combination of elevating and rotating the camera. Taken together, elevating the camera produces significantly lower body weight judgments across all conditions. An additional rotation does not sufficiently improve this effect. Lowering the camera produces significantly higher body weight judgments across all conditions. However, an additional rotation has a significant effect on perceived body weight (lower body weight judgments). 


\section{GENERAL DISCUSSION}

The main goal of this study was to reveal the impact of perspective on persons depicted via selfies. In two studies, we revealed clear effects of perspective on higher cognitive processes (namely the perception of person-related variables on the basis of facial depictions). Research on selfies has revealed that persons who shoot selfies want to express their mood, their personality and even their lifestyle via selfies, so they try to optimize this information by intuitively adapting the camera position (see e.g., Sorokowska et al., 2016). Previous work documented that in cases of classical portraits there were a lot of compositional suggestions and artificial rules which were applied to gain pictures of high appeal, e.g., the "Golden Ratio Rule" or the "Rule of Thirds" or general placement principles of facial features (see e.g., Tyler, 1998a,b; Westphalen, 2016). However, scientific research is quite far from achieving consistent results about the meaningfulness and effects of these rules in general (e.g., Green, 1995; Höge, 1997; McManus and Weatherby, 1997; McManus and Thomas, 2007; Bertamini et al., 2011). In contrast, regarding the social phenomenon of taking selfies, one may find only a small number of suggestions, often in a relative unsystematic way, for taking the "best" selfie (scientificly investigated by e.g., Yeh and Lin, 2014; Kalayeh et al., 2015) and some photographic rules like the "high-angle shot" (e.g., Mamer, 2013). However, there is little knowledge about whether and how exactly these aspects may have an impact on the perception of a given face. Moreover, there are some hints toward a general deviation from known photographic principles in selfies (Bruno et al., 2014) and the impact of a typical selfie-style perspective has yet to be investigated.

Accordingly, our results suggest that perspective has a significant impact on the perception of the beholder, especially for attractiveness, helpfulness, sympathy, intelligence, and associated body weight: Study 1 investigated the impact of viewing perspective in cases of more classical portraits and revealed that showing the right cheek (showing the right hemiface) positively affects the perception of attractiveness, helpfulness, sympathy, intelligence and body weight. This finding is in accordance with the finding that the right side of the owner's face (right hemiface) affects the perception of attractiveness, age and gender (Zaidel et al., 1995; Burt and Perrett, 1997; Dunstan and Lindell, 2012) more than the left side (left hemiface) but is in some contrast to findings that emotional aspects can be derived better and more accurately from the left side of the owner's face (e.g., Zaidel et al., 1995; Kramer and Ward, 2011; Lindell, 2013a,b; Low and Lindell, 2016). However, with respect to the perceived attractiveness, we found comparative lager effects for the left hemiface, contrasting past research by others (for instance, Zaidel et al., 1995; Burt and Perrett, 1997; Dunstan and Lindell, 2012; but also see Sitton et al., 2006). It is important to mention that past research (but see Kramer and Ward, 2011) did not use 2D stimuli generated from real 3D face models for that kind of research question. Schneider et al. (2012) suggested that differences in perceptual aspects (e.g., perceived body weight on the basis of faces) are strongly dependent on depth information, hence viewing perspective affects respective ratings.
In Study 2, we investigated the effect of more selfie-style viewing perspectives (typical combination of camera rotation and camera pitch) and only found effects for attractiveness, helpfulness and body weight. Importantly, elevating and rotating had a positive effect on these variables and was slightly more pronounced for the right side of the face on average. Lowering the camera only had negative effects on perceived attractiveness and body weight. Regarding the perceived body weight, an additional rotation of the camera reduced the effect of a lowered/raised camera, supporting previous findings relating to the height-weight illusion (Schneider et al., 2012). The rest of the personalityrelated variables remained unaffected from a statistical point of view, although they showed slightly higher ratings for right-sided and elevated snapshots on a purely numerical basis.

How can the complex data pattern be interpreted? First of all: Perspective has a significant impact on the perception of highercognitive variables (such as person-related variables) on the basis of faces. Secondly: Effects of perspective were in contrast to some past findings (for example, higher effects for the right side of the face on average in Study 2 and larger effects for attractiveness for the left side of the face in Study 1 and 2) suggesting that selfies constitute an own class of pictorial presentations of a person. This is supported by the findings of Bruno et al. (2014) showing a systematic deviation from known photographic rules in selfies. Furthermore, our results highlight the importance of the visibility of certain features in facial stimuli, per se (e.g., regarding the perception of dominance, our results underline the visibility of the neck as an important cue to masculinity and dominance). Thirdly: Interestingly, for most of the variables effects were significant for the $30^{\circ}$ head turn (left and right hemiface) images, but not the $15^{\circ}$ head turn images. We have at least two reasons for this discrepancy in mind: On the one hand, the $15^{\circ}$ rotation is just too similar to the frontal condition, at least to detect any differences from the frontal view by means of the given experimental setting with limited sample sizes which were only capable of revealing effect sizes of small to medium effect sizes but not, for example, very small effects. On the other hand, referring to research papers which systematically varied other kinds of rotation, e.g., planar rotations, we also observed a certain range of rotations for which essential variables did not change [e.g., Carbon et al., 2007 did not detect any significant change of the target variable grotesqueness as well as the reaction time (RT) associated with this assessment]. Fourthly: In contrast to the common standpoint that we are able to make meaningful suggestions about "how to take the perfect selfie," our results indicate that we are a long way from having any clear references.

We would also like to mention some limitations of this study: Past research revealed that direct vs. averted gazes have a direct impact on the perception of a given face (e.g., Kampe et al., 2001; Ewing et al., 2010). More precisely, these studies revealed that an averted gaze has a negative effect on the perception of attractiveness. However, the effect of the combination of averted head plus direct gaze vs. frontal face plus averted gaze across different viewing perspectives on the perception 
of higher cognitive variables (like those we used) has not yet been investigated. In this study, we did not investigate such a combination, which would incidentally be very much in accord with some Renaissance portraits like La Gioconda by Leonardo da Vinci (see details on the perspective of the Mona Lisa in Carbon and Hesslinger, 2013). Future research should address such further settings to enrich the existing knowledge base on selfies. Another weakness of the present study is that we neither could control the actual size of the presented face on the monitor nor the actual viewing distance. Moreover, we must expect that display color, contrast and brightness were not at the same level across all participants. This might affect the perception of a face dramatically. However, the fact that we could replicate the height-weight illusion (Schneider et al., 2012) makes it conjecturable that other effects were relative stable. Similarly, other studies (e.g., ten Cate, 2002; Churches et al., 2012) used relatively unstandardized images that could not be controlled along those variables, and though revealed consistent results.

Despite all the back draws you always face with standardized and systematically varied material, such experimental material can test already small effects which might be tested with more ecologically valid material in the field later on. We hope that our study contributes to the understanding on how perspective can change the assessment of higher cognitive variables. This will help to sensitize selfie-ists how powerful

\section{REFERENCES}

Akselrod-Ballin, A., and Ullman, S. (2008). Distinctive and compact features. Image Vis. Comput. 26, 1269-1276. doi: 10.1016/j.imavis.2008.03.005

Banducci, S. A., Karp, J. A., Thrasher, M., and Rallings, C. (2008). Ballot photographs as cues in low-information elections. Polit. Psychol. 29, 903-917. doi: 10.1111/j.1467-9221.2008.00672.x

Baranowski, A., and Hecht, H. (in press). Effect of camera angle on perception of trust and attractiveness. Empirical Studies of the Arts.

Baranowski, A., Leder, H., Schneider, T. M., Hemmerich, W., and Hecht, H. (2016). "Facial attractiveness and the cone of gaze," in Abstracts of the 58th Conference of Experimental Psycholoy, eds J. Funke, J. Rummel, and A. Voss (Heidelberg; Lengerich: Pabst Science Publishers), 19-20.

Baumeister, R. F., Chesner, S. P., Senders, P. S., and Tice, D. M. (1988). Who's in charge here? Pers. Soc. Psychol. Bull. 14, 17-22. doi: 10.1177/0146167288141002

Berggren, N., Jordahl, H., and Poutvaara, P. (2010). The looks of a winner: beauty and electoral success. J. Public Econ. 94, 8-15. doi: 10.1016/j.jpubeco.2009.11.002

Berry, D. S., and Brownlow, S. (1989). Were the physiognomists right? Personality-correlates of facial babyishness. Pers. Soc. Psychol. Bull 15, 266-279. doi: $10.1177 / 0146167289152013$

Bertamini, M., Bennett, K. M., and Bode, C. (2011). The anterior bias in visual art: the case of images of animals. Laterality 16, 673-689. doi: 10.1080/1357650x.2010.508219

Borod, J. C., Kent, J., Koff, E., Martin, C., and Alpert, M. (1988). Facial asymmetry while posing positive and negative emotions support for the right-hemisphere hypothesis. Neuropsychologia 26, 759-764. doi: 10.1016/0028-3932(88)90013-9

Bruce, V., Burton, M., Doyle, T., and Dench, N. (1989). Further experiments on the perception of growth in three dimensions. Percept. Psychophys. 46, 528-536.

Bruno, N., and Bertamini, M. (2013). Self-Portraits: smartphones reveal a side bias in non-artists. PLoS ONE 8:e55141. doi: 10.1371/journal.pone.0055141

Bruno, N., Gabriele, V., Tasso, T., and Bertamini, M. (2014). Selfies reveal systematic deviations from known principles of photographic composition. Art Percept. 2, 45-58. doi: 10.1163/22134913-00002027 the use of perspective might be in conveying their inner states.

\section{ETHICS STATEMENT}

The study was reviewed and approved by the Ethics Committee of the University of Bamberg, Germany. Its protocol was approved.

\section{AUTHOR CONTRIBUTIONS}

TS was responsible for collecting and analyzing/interpreting data as well as for writing this manuscript. CC was responsible for supervision (initial idea and experimental design improvements), result interpretation and critical manuscript reviewing. Both authors agree to be accountable for the content of the work.

\section{ACKNOWLEDGMENTS}

We would like to thank Florence Bockting and Vivien Vorndran for their assistance during data collection. We would also thank the three reviewers which take great care to improve the manuscript and provided very helpful further ideas. Last but not least, we would like to thank Alun H. Brown and Miriam Ashford for proofreading the manuscript.

Burke, D., and Sulikowski, D. (2010). A new viewpoint on the evolution of sexually dimorphic human faces. Evol. Psychol. 8, 573-585. doi: 10.1177/147470491000800404

Burke, D., Taubert, J., and Higman, T. (2007). Are face representations viewpoint dependent? A stereo advantage for generalising across different views of faces. Vis. Res. 47, 2164-2169. doi: 10.1016/j.visres.2007.04.018

Burt, D. M., and Perrett, D. I. (1997). Perceptual asymmetries in judgements of facial attractiveness, age, gender, speech and expression. Neuropsychologia 35, 685-693. doi: 10.1016/S0028-3932(96)00111-X

Butler, S., Gilchrist, I. D., Burt, D. M., Perrett, D. I., Jones, E., and Harvey, M. (2005). Are the perceptual biases found in chimeric face processing reflected in eye-movement patterns? Neuropsychologia 43, 52-59. doi: 10.1016/j.neuropsychologia.2004.06.005

Cacioppo, J. T., and Petty, R. E. (1981). Lateral asymmetry in the expression of cognition and emotion. J. Exp. Psychol. Hum. Percept. Perform. 7, 333-341. doi: 10.1037/0096-1523.7.2.333

Campbell, D. T. (1975). On the conflicts between biological and social evolution and between psychology and moral tradition. Am. Psychol. 30, 1103-1126. doi: 10.1037/0003-066X.30.12.1103

Carbon, C. C. (2017). Universal principles of depicting oneself across the centuries: from Renaissance self-portraits to selfie-photographs. Front. Psychol. 8:245. doi: 10.3389/fpsyg.2017.00245

Carbon, C. C., and Hesslinger, V. M. (2013). Da Vinci's Mona Lisa entering the next dimension. Perception 42, 887-893. doi: 10.1068/p7524

Carbon, C. C., and Leder, H. (2006). When faces are heads: view-dependent recognition of faces altered relationally or componentially. Swiss J. Psychol. 65, 245-252. doi: 10.1024/1421-0185.65.4.245

Carbon, C. C., Grüter, T., Grüter, M., Weber, J. E., and Lueschow, A. (2010). Dissociation of facial attractiveness and distinctiveness processing in congenital prosopagnosia. Vis. Cogn. 18, 641-654. doi: 10.1080/135062809034 62471

Carbon, C. C., Gruter, T., Weber, J. E., and Lueschow, A. (2007). Faces as objects of non-expertise: processing of thatcherised faces in congenital prosopagnosia. Perception 36, 1635-1645. doi: 10.1068/p5467 
Chiao, J. Y., Adams, R. B., Tse, P. U., Lowenthal, W. T., Richeson, J. A., and Ambady, N. (2008). Knowing who's boss: fMRI and ERP investigations of social dominance perception. Group Process. Intergroup Relat. 11, 201-214. doi: $10.1177 / 1368430207088038$

Churches, O., Callahan, R., Michalski, D., Brewer, N., Turner, E., Keage, H. A. D., et al. (2012). How academics face the world: a study of 5829 homepage pictures. PLoS ONE 7:e38940. doi: 10.1371/journal.pone.0038940

Coetzee, V., Chen, J. Y., Perrett, D. I., and Stephen, I. D. (2010). Deciphering faces: quantifiable visual cues to weight. Perception 39, 51-61. doi: 10.1068/p6560

Coetzee, V., Perrett, D. I., and Stephen, I. D. (2009). Facial adiposity: a cue to health? Perception 38, 1700-1711. doi: 10.1068/p6423

Cohen, J. (1988). Statistical Power Analysis for the Behavioral Sciences, $2 n d$ Edn. Hillsdale, NJ: Lawrence Erlbaum Associates.

Costa, P. T., and McCrae, R. R. (1992). NEO Personality Inventory Professional Manual. Odessa, FL: Psychological Assessment Resources.

Cunningham, M. R., Barbee, A. P., and Pike, C. L. (1990). What do women want facialmetric assessment of multiple motives in the perception of male facial physical attractiveness. J. Pers. Soc. Psychol. 59, 61-72. doi: 10.1037/0022-3514.59.1.61

Dion, K., Berscheid, E., and Walster, E. (1972). What is beautiful is good. J. Pers. Soc. Psychol. 24, 285-290. doi: 10.1037/h0033731

Dopson, W. G., Beckwith, B. E., Tucker, D. M., and Bullard-Bates, P. C. (1984). Asymmetry of facial expression in spontaneous emotion. Cortex 20, 243-251. doi: 10.1016/S0010-9452(84)80041-6

Dunstan, C. J., and Lindell, A. K. (2012). Hemifacial preferences for the perception of emotion and attractiveness differ with the gender of the one beheld. Cogn. Emot. 26, 907-915. doi: 10.1080/02699931.2011.621931

Eagly, A. H., Makhijani, M. G., Ashmore, R. D., and Longo, L. C. (1991). What is beautiful is good, but: a meta-analytic review of research on the physical attractiveness stereotype. Psychol. Bull. 110, 109-128. doi: 10.1037/0033-2909.110.1.109

Ekman, P., Hager, J. C., and Friesen, W. V. (1981). The symmetry of emotional and deliberate facial actions. Psychophysiology 18, 101-106. doi: 10.1111/j.1469-8986.1981.tb02919.x

Ewing, L., Rhodes, G., and Pellicano, E. (2010). Have you got the look? Gaze direction affects judgements of facial attractiveness. Vis. Cogn. 18, 321-330. doi: 10.1080/13506280902965599

Favelle, S. K., Palmisano, S., and Avery, G. (2011). Face viewpoint effects about three axes: the role of configural and featural processing. Perception 40, 761-784. doi: 10.1068/p6878

Fink, B., Neave, N., Manning, J. T., and Grammer, K. (2006). Facial symmetry and judgements of attractiveness, health and personality. Pers. Individ. Dif. 41, 491-499. doi: 10.1016/J.Paid.2006.01.017

Folstad, I., and Karter, A. J. (1992). Parasites, bright males, and the immunocompetence handicap. Am. Nat. 139, 603-622. doi: 10.1086/285346

Frederick, D. A., and Haselton, M. G. (2007). Why is muscularity sexy? Tests of the fitness indicator hypothesis. Pers. Soc. Psychol. Bull. 33, 1167-1183. doi: $10.1177 / 0146167207303022$

Furnham, A., and Cheng, H. (2015). Early indicators of adult trait Agreeableness. Pers. Individ. Dif. 73, 67-71. doi: 10.1016/j.paid.2014.09.025

Furnham, A., Swami, V., and Shah, K. (2006). Body weight, waist-to-hip ratio and breast size correlates of ratings of attractiveness and health. Pers. Individ. Dif. 41, 443-454. doi: 10.1016/j.paid.2006.02.007

Girden, E. R. (1992). ANOVA: Repeated Measures. New York, NY: SAGE Publications.

Goffaux, V., Rossion, B., Sorger, B., Schiltz, C., and Goebel, R. (2009). Face inversion disrupts the perception of vertical relations between features in the right human occipito-temporal cortex. J. Neuropsychol. 3, 45-67. doi: $10.1348 / 174866408 \times 292670$

Grammer, K., and Thornhill, R. (1994). Human (Homo-Sapiens) facial attractiveness and sexual selection: the role of symmetry and averageness. $J$. Comp. Psychol. 108, 233-242. doi: 10.1037/0735-7036.108.3.233

Green, C. D. (1995). All that glitters a review of psychological research on the aesthetics of the golden section. Perception 24, 937-968. doi: 10.1068/p240937

Guntuku, S. C., Qiu, L., Roy, S., Lin, W., and Jakhetiya, V. (2015). "Do others perceive you as you want them to?: Modeling personality based on selfies," in Paper Presented at the Proceedings of the 1st International Workshop on Affect; Sentiment in Multimedia (Brisbane, QLD).
Hahn, J., and Blass, T. (1997). Dating partner preferences: a function of similarity of love styles. J. Soc. Behav. Pers. 12, 595-610.

Höge, H. (1997). The golden section hypothesis its last funeral. Empir. Stud. Arts 15, 233-255. doi: 10.2190/2pnh-8tt0-emc5-ftw5

Hogg, M. A., and Vaughan, G. M. (2013). Social Psychology, 7 Edn. Essex: Pearson Education Limited.

Hole, G., and George, P. (2011). Evidence for holistic processing of facial age. Vis. Cogn. 19, 585-615. doi: 10.1080/13506285.2011.562076

Huynh, H., and Feldt, L. S. (1976). Estimation of the Box correction for degrees of freedom from sample data in randomized block and split-plot designs. J. Educ. Behav. Stat. 1, 69-82. doi: 10.3102/10769986001001069

Indersmitten, T., and Gur, R. C. (2003). Emotion processing in chimeric faces: hemispheric asymmetries in expression and recognition of emotions. $J$. Neurosci. 23, 3820-3825.

Jones, A. L., Kramer, R. S. S., and Ward, R. (2012). Signals of personality and health: the contributions of facial shape, skin texture, and viewing angle. J. Exp. Psychol. Hum. Percept. Perform. 38, 1353-1361. doi: 10.1037/A0027078

Jones, B. C., Little, A. C., Penton-Voak, I. S., Tiddeman, B. P., Burt, D. M., and Perrett, D. I. (2001). Facial symmetry and judgements of apparent health support for a good genes explanation of the attractiveness-symmetry relationship. Evol. Hum. Behav. 22, 417-429. doi: 10.1016/S1090-5138(01)00083-6

Jones, D. (1995). Sexual selection, physical attractiveness, and facial neotenycross-cultural evidence and implications. Curr. Anthropol. 36, 723-748. doi: 10.1086/204427

Kalayeh, M. M., Seifu, M., LaLanne, W., and Shah, M. (2015). "How to take a good selfie?", in Paper Presented at the Proceedings of the 23rd ACM International Conference on Multimedia (Brisbane, QLD).

Kampe, K. K. W., Frith, C. D., Dolan, R. J., and Frith, U. (2001). Reward value of attractiveness and gaze making eye contact enhances the appeal of a pleasing face, irrespective of gender. Nature 413, 589-589. doi: 10.1038/350 98149

Keating, C. F. (1985). Gender and the physiognomy of dominance and attractiveness. Soc. Psychol. Q. 48, 61-70. doi: 10.2307/3033782

King, A., and Leigh, A. (2009). Beautiful politicians. Kyklos 62, 579-593. doi: 10.1111/j.1467-6435.2009.00452.x

Kowner, R. (1995). Laterality in facial expressions and its effect on attributions of emotion and personality a reconsideration. Neuropsychologia 33, 539-559. doi: 10.1016/0028-3932(94)00137-E

Kramer, R. S. S., and Ward, R. (2011). Different signals of personality and health from the two sides of the face. Perception 40, 549-562. doi: 10.1068/p6856

Leder, H., and Carbon, C. C. (2005). When context hinders! Learn-test compatibility in face recognition. Q. J. Exp. Psychol. A 58, 235-250. doi: 10.1080/02724980343000936

Leder, H., Mitrovic, A., and Goller, J. (2016). How beauty determines gaze! facial attractiveness and gaze duration in images of real world scenes. Iperception 7 , 1-12. doi: 10.1177/2041669516664355

Leder, H., Tinio, P. P, Fuchs, I. M., and Bohrn, I. (2010). When attractiveness demands longer looks: the effects of situation and gender. Q. J. Exp. Psychol. 63, 1858-1871. doi: 10.1080/17470211003605142

Leiner, D. (2014). SoSci Survey. Available online at: http://www.soscisurvey.de/

Lindell, A. K. (2013a). Capturing their best side? Did the advent of the camera influence the orientation artists chose to paint and draw in their self-portraits? Laterality 18, 319-328. doi: 10.1080/1357650x.2012.673622

Lindell, A. K. (2013b). The silent social/emotional signals in left and right cheek poses: a literature review. Laterality 18, 612-624. doi: 10.1080/1357650x.2012.737330

Lindell, A. K. (2016). No cheek bias: posing orientation in van Gogh's portraits and self-portraits. Empir. Stud. Arts, 1-13. doi: 10.1177/0276237416661988

Lindell, A. K., and Savill, N. J. (2010). Time to turn the other cheek? The influence of left and right poses on perceptions of academic specialisation. Laterality 15, 639-650. doi: 10.1080/13576500903201784

Lishner, D. A., Batson, C. D., and Huss, E. (2011). Tenderness and sympathy: distinct empathic emotions elicited by different forms of need. Pers. Soc. Psychol. Bull. 37, 614-625. doi: 10.1177/0146167211403157

Low, J. Y., and Lindell, A. K. (2016). Featural information is sufficient to produce a left cheek bias for happiness perception. Brain Cogn. 107, 10-15. doi: 10.1016/j.bandc.2016.06.001 
Luo, S. H., and Klohnen, E. C. (2005). Assortative mating and marital quality in newlyweds: a couple-centered approach. J. Pers. Soc. Psychol. 88, 304-326. doi: 10.1037/0022-3514.88.2.304

Mamer, B. (2013). Film Production Technique: Creating the Accomplished Image. Stamford, CT: Cengage Learning.

Maner, J. K., Gailliot, M. T., Rouby, D. A., and Miller, S. L. (2007). Can't take my eyes off you: attentional adhesion to mates and rivals. J. Pers. Soc. Psychol. 93, 389-401. doi: 10.1037/0022-3514.93.3.389

Maner, J. K., Kenrick, D. T., Becker, D. V., Delton, A. W., Hofer, B., Wilbur, C. J., et al. (2003). Sexually selective cognition: beauty captures the mind of the beholder. J. Pers. Soc. Psychol. 85, 1107-1120. doi: 10.1037/0022-3514.85.6.107

McArthur, L. Z., and Apatow, K. (1984). Impressions of baby-faced adults. Soc. Cogn. 2, 315-342. doi: 10.1521/soco.1984.2.4.315

McArthur, L. Z., and Berry, D. S. (1987). Cross-cultural agreement in perceptions of babyfaced adults. J. Cross Cult. Psychol. 18, 165-192. doi: $10.1177 / 0022002187018002003$

McManus, I. C., and Humphrey, N. K. (1973). Turning the feft cheek. Nature 243, 271-272. doi: $10.1038 / 243271 \mathrm{a} 0$

McManus, I. C., and Thomas, P. (2007). Eye centring in portraits: a theoretical and empirical evaluation. Perception 36, 167-182. doi: 10.1068/p5578

McManus, I. C., and Weatherby, P. (1997). The golden section and the aesthetics of form and composition: a cognitive model. Empir. Stud. Arts 15, 209-232. doi: 10.2190/wwcr-vwhv-2y2w-91ee

Mignault, A., and Chaudhuri, A. (2003). The many faces of a neutral face: head tilt and perception of dominance and emotion. J. Nonverbal Behav. 27, 111-132. doi: 10.1023/A:1023914509763

Mobius, M. M., and Rosenblat, T. S. (2006). Why beauty matters. Am. Econ. Rev. 96, 222-235. doi: 10.1257/000282806776157515

Moreno, C. R., Borod, J. C., Welkowitz, J., and Alpert, M. (1990). Lateralization for the expression and perception of facial emotion as a function of age. Neuropsychologia 28, 199-209. doi: 10.1016/0028-3932(90)90101-S

Naumann, L. P., Vazire, S., Rentfrow, P. J., and Gosling, S. D. (2009). Personality judgments based on physical appearance. Pers. Soc. Psychol. Bull. 35, 1661-1671. doi: 10.1177/0146167209346309

Nedelec, J. L., and Beaver, K. M. (2014). Physical attractiveness as a phenotypic marker of health: an assessment using a nationally representative sample of American adults. Evol. Hum. Behav. 35, 456-463. doi: 10.1016/j.evolhumbehav.2014.06.004

Nestler, S., Egloff, B., Küfner, A. C. P., and Back, M. D. (2012). An integrative lens model approach to bias and accuracy in human inferences: hindsight effects and knowledge updating in personality judgments. J. Pers. Soc. Psychol. 103, 689-717. doi: 10.1037/a0029461

Neuberg, S. L., Kenrick, D. T., and Schaller, M. (2010). "Evolutionary social psychology," in Handbook of Social Psychology, Vol. 2, Edn 5, eds S. T. Fiske, D. T. Gilbert, and G. Lindzey (Hoboken, NJ: John Wiley \& Sons), 761-796.

Newell, F. N., Chiroro, P., and Valentine, T. (1999). Recognizing unfamiliar faces: the effects of distinctiveness and view. Q. J. Exp. Psychol. A 52, 509-534. doi: 10.1080/027249899391179

Nicholls, M. E. R., Clode, D., Wood, S. J., and Wood, A. G. (1999). Laterality of expression in portraiture: putting your best cheek forward. Proc. R. Soc. B Biol. Sci. 266, 1517-1522. doi: 10.1098/rspb.1999.0809

Nicholls, M. E. R., Wolfgang, B. J., Clode, D., and Lindell, A. K. (2002). The effect of left and right poses on the expression of facial emotion. Neuropsychologia 40, 1662-1665. doi: 10.1016/S0028-3932(02)00024-6

Oberfeld, D., and Franke, T. (2013). Evaluating the robustness of repeated measures analyses: the case of small sample sizes and nonnormal data. Behav. Res. Methods 45, 792-812. doi: 10.3758/s13428-012-0281-2

Okubo, M., Ishikawa, K., and Kobayashi, A. (2013). No trust on the left side: hemifacial asymmetries for trustworthiness and emotional expressions. Brain Cogn. 82, 181-186. doi: 10.1016/j.bandc.2013.04.004

Otta, E., Lira, B. B., Delevati, N. M., Cesar, O. P., and Pires, C. S. G. (1994). The effect of smiling and of head tilting on person perception. J. Psychol. 128, 323-331. doi: 10.1080/00223980.1994.9712736

Penton-Voak, I. S., Jones, B. C., Little, A. C., Baker, S., Tiddeman, B., Burt, D. M., et al. (2001). Symmetry, sexual dimorphism in facial proportions and male facial attractiveness. Proc. R. Soc. Lond. B Biol. Sci. 268, 1617-1623. doi: $10.1098 / \mathrm{rspb} .2001 .1703$
Perrett, D. I., Lee, K. J., Penton-Voak, I., Rowland, D., Yoshikawa, S., Burt, D. M., et al. (1998). Effects of sexual dimorphism on facial attractiveness. Nature 394, 884-887. doi: $10.1038 / 29772$

Perry, S. L. (2015). A match made in heaven? Religion-based marriage decisions, marital quality, and the moderating effects of spouse's religious commitment. Soc. Indic. Res. 123, 203-225. doi: 10.1007/s11205-014-0730-7

Qiu, L., Lu, J. H., Yang, S. S., Qu, W. N., and Zhu, T. S. (2015). What does your selfie say about you? Comput. Hum. Behav. 52, 443-449. doi: $10.1016 /$ j.chb.2015.06.032

Re, D. E., and Rule, N. O. (2016). Heavy matters: the relationship between just noticeable differences in perceptions of facial adiposity and facial attractiveness. Soc. Psychol. Pers. Sci. 7, 69-76. doi: 10.1177/1948550615599829

Re, D. E., Dzhelyova, M., Holzleitner, I. J., Tigue, C. C., Feinberg, D. R., and Perrett, D. I. (2012). Apparent height and body mass index influence perceived leadership ability in three-dimensional faces. Perception 41, 1477-1485. doi: 10.1068/P7342

Re, D. E., Hunter, D. W., Coetzee, V., Tiddeman, B. P., Xiao, D., DeBruine, L. M., et al. (2013). Looking like a leader-facial shape predicts perceived height and leadership ability. PLoS ONE 8:e80957. doi: 10.1371/journal.pone.0080957

Reis, V. A., and Zaidel, D. W. (2001). Functional asymmetry in the human face: perception of health in the left and right sides of the face. Laterality 6, 225-231. doi: 10.1080/713754415

Rhodes, G., Zebrowitz, L. A., Clark, A., Kalick, S. M., Hightower, A., and McKay, R. (2001). Do facial averageness and symmetry signal health? Evol. Hum. Behav. 22, 31-46. doi: 10.1016/S1090-5138(00)00060-X

Richler, J. J., Mack, M. L., Palmeri, T. J., and Gauthier, I. (2011). Inverted faces are (eventually) processed holistically. Vis. Res. 51, 333-342. doi: 10.1016/j.visres.2010.11.014

Rule, N. O., Adams, R. B., Ambady, N., and Freeman, J. B. (2012). Perceptions of dominance following glimpses of faces and bodies. Perception 41, 687-706. doi: $10.1068 / \mathrm{p} 7023$

Sackeim, H. A., Gur, R. C., and Saucy, M. C. (1978). Emotions are expressed more intensely on the left side of the face. Science 202, 434-436. doi: $10.1126 /$ science. 705335

Schneider, T. M., Hecht, H., and Carbon, C. C. (2012). Judging body weight from faces: the height-weight illusion. Perception 41, 121-124. doi: 10.1068/p7140

Schneider, T. M., Hecht, H., Stevanov, J., and Carbon, C. C. (2013). Cross-ethnic assessment of body weight and height on the basis of faces. Pers. Individ. Dif. 55, 356-360. doi: 10.1016/j.paid.2013.03.022

Shackelford, T. K., and Larsen, R. J. (1997). Facial asymmetry as an indicator of psychological, emotional, and physiological distress. J. Pers. Soc. Psychol. 72, 456-466.

Sitton, S. C., Waite, L., and Rivers, S. C. (2006). Perception of traits from normal, mirror and chimeric images of faces. Am. J. Psychol. Res. 2, 14-20.

Sorokowska, A., Oleszkiewicz, A., Frackowiak, T., Pisanski, K., Chmiel, A., and Sorokowski, P. (2016). Selfies and personality: who posts self-portrait photographs? Pers. Individ. Dif. 90, 119-123. doi: 10.1016/j.paid.2015.10.037

Stephan, B. C. M., and Caine, D. (2007). What is in a view? The role of featural information in the recognition of unfamiliar faces across viewpoint transformation. Perception 36, 189-198. doi: 10.1068/p5627

Stevens, J. R., Cushman, F. A., and Hauser, M. D. (2005). Evolving the psychological mechanisms for cooperation. Annu. Rev. Ecol. Evol. Syst. 36, 499-518. doi: 10.1146/annurev.ecolsys.36.113004.083814

Stewart, J. E. (1980). Defendant's attractiveness as a factor in the outcome of criminal trials: an observational study. J. Appl. Soc. Psychol. 10, 348-361. doi: 10.1111/j.1559-1816.1980.tb00715.x

Swaddle, J. P., and Reierson, G. W. (2002). Testosterone increases perceived dominance but not attractiveness in human males. Proc. Biol. Sci. 269, 2285-2289. doi: 10.1098/rspb.2002.2165

Swami, V., and Tovee, M. J. (2005). Male physical attractiveness in Britain and Malaysia: a cross-cultural study. Body Image 2, 383-393. doi: 10.1016/j.bodyim.2005.08.001

Swami, V., and Tovee, M. J. (2008). Female physical attractiveness in Britain and Malaysia: a cross-cultural study. Body Image 2, 115-128. doi: 10.1016/j.bodyim.2005.02.002

Swami, V., Caprario, C., Tovee, M. J., and Furnham, A. (2006). Female physical attractiveness in Britain and Japan: a cross-cultural study. Eur. J. Pers. 20, 69-81. doi: $10.1002 /$ Per.568 
Swami, V., Frederick, D. A., Aavik, T., Alcalay, L., Allik, J., Anderson, D., et al. (2010). The attractive female body weight and female body dissatisfaction in 26 countries across 10 world regions: results of the International body project I. Pers. Soc. Psychol. Bull. 36, 309-325. doi: 10.1177/0146167209359702

Tanaka, J. W., and Farah, M. J. (1993). Parts and wholes in face recognition. Q. J. Exp. Psychol. A 46, 225-245.

Teijeiro-Mosquera, L., Biel, J. I., Alba-Castro, J. L., and Gatica-Perez, D. (2015). What your face vlogs about: expressions of emotion and Big-Five traits impressions in YouTube. IEEE Trans. Affect. Comput. 6, 193-205. doi: 10.1109/Taffc.2014.2370044

ten Cate, C. (2002). Posing as professor: laterality in posing orientation for portraits of scientists. J. Nonverbal Behav. 26, 175-192. doi: 10.1023/A:1020713416442

Thompson, E. R. (2008). Development and validation of an international English Big-Five mini-markers. Pers. Individ. Dif. 45, 542-548. doi: 10.1016/j.paid.2008.06.013

Thornhill, R., and Gangestad, S. W. (1993). Human facial beauty averageness, symmetry, and parasite resistance. Hum. Nat. 4, 237-269. doi: $10.1007 / \mathrm{Bf} 02692201$

Thornhill, R., and Grammer, K. (1999). The body and face of woman: one ornament that signals quality? Evol. Hum. Behav. 20, 105-120. doi: 10.1016/S1090-5138(98)00044-0

Tinlin, R. M., Watkins, C. D., Welling, L. L., DeBruine, L. M., Al-Dujaili, E. A., and Jones, B. C. (2013). Perceived facial adiposity conveys information about women's health. Br. J. Psychol. 104, 235-248. doi: $10.1111 / j .2044-8295.2012 .02117 . x$

Toledano, E. (2012). The looking-glass ceiling: appearance-based discrimination in the workplace. Cardozo J. Law Gend. 19, 683-714.

Tovee, M. J., Maisey, D. S., Emery, J. L., and Cornelissen, P. L. (1999). Visual cues to female physical attractiveness. Proc. R. Soc. Lond. B Biol. Sci. 266, 211-218. doi: $10.1098 / \mathrm{rspb} .1999 .0624$

Tovee, M. J., Reinhardt, S., Emery, J. L., and Cornelissen, P. L. (1998). Optimum body-mass index and maximum sexual attractiveness. Lancet 352, 548-548. doi: 10.1016/S0140-6736(05)79257-6

Tovee, M. J., Swami, V., Furnham, A., and Mangalparsad, R. (2006). Changing perceptions of attractiveness as observers are exposed to a different culture. Evol. Hum. Behav. 27, 443-456. doi: 10.1016/j.evolhumbehav.2006.05.004

Turner, D. D. (2005). Altruism - is it still an anomaly? Trends Cogn. Sci. 9, 317-318. doi: 10.1016/j.tics.2005.05.007

Tyler, C. W. (1998a). Eye placement principles in portraits and figure studies over the past two millennia. Hum. Vis. Electron. Imaging III 3299, 431-438. doi: $10.1117 / 12.320133$

Tyler, C. W. (1998b). Painters centre one eye in portraits. Nature 392, 877-878. doi: $10.1038 / 31833$

Valentin, D., Abdi, H., and Edelman, B. (1999). From rotation to disfiguration: testing a dual-strategy model for recognition of faces across view angles. Perception 28, 817-824. doi: 10.1068/p2932
Valentin, D., Abdi, H., Edelman, B., and Posamentier, M. (2001). "2D or not 2D? That is the question: what can we learn from computational models operating on two-dimensional representations of faces?," in Computational, Geometric, and Process Perspectives on Facial Cognition: Contexts and Challenges, Scientific Psychology Series, ed M. J. Wenger (Mahwah, NJ: Erlbaum), 429-465.

Valentine, T. (1991). A unified account of the effects of distinctiveness, inversion, and race in face recognition. Q. J. Exp. Psychol. A 43, 161-204. doi: 10.1080/14640749108400966

van Straaten, I., Holland, R. W., Finkenauer, C., Hollenstein, T., and Engels, R. C. (2010). Gazing behavior during mixed-sex interactions: sex and attractiveness effects. Arch. Sex. Behav. 39, 1055-1062. doi: 10.1007/s10508-0099482-x

Watson, D., Klohnen, E. C., Casillas, A., Simms, E. N., Haig, J., and Berry, D. S. (2004). Match makers and deal breakers: analyses of assortative mating in newlywed couples. J. Pers. 72, 1029-1068. doi: 10.1111/j.0022-3506.2004.00289.x

Westphalen, C. (2016). Die Große Fotoschule: Das Handbuch zur Digitalen Fotografie [The great photo bible: Handbook of digital photography], 3rd Edn. Bonn: Rheinwerk-Verlag.

Wickham, L. H. V., and Morris, P. E. (2003). Attractiveness, distinctiveness, and recognition of faces: attractive faces can be typical or distinctive but are not better recognized. Am. J. Psychol. 116, 455-468. doi: 10.2307/14 23503

Wilson, E. O. (2000). Sociobiology: The New Synthesis. Cambridge, MA: Harvard University Press.

Yeh, M.-C., and Lin, H.-W. (2014). "Virtual Portraitist: aesthetic evaluation of selfies based on angle," in Paper Presented at the Proceedings of the 22nd ACM International Conference on Multimedia, (Orlando, FL).

Zaidel, D. W., and Cohen, J. A. (2005). The face, beauty, and symmetry: perceiving asymmetry in beautiful faces. Int. J. Neurosci. 115, 1165-1173. doi: $10.1080 / 00207450590914464$

Zaidel, D. W., Chen, A. C., and German, C. (1995). She is not a beauty even when she smiles: possible evolutionary basis for a relationship between facial attractiveness and hemispheric specialization. Neuropsychologia 33, 649-655. doi: 10.1016/0028-3932(94)00135-C

Conflict of Interest Statement: The authors declare that the research was conducted in the absence of any commercial or financial relationships that could be construed as a potential conflict of interest.

Copyright (c) 2017 Schneider and Carbon. This is an open-access article distributed under the terms of the Creative Commons Attribution License (CC BY). The use, distribution or reproduction in other forums is permitted, provided the original author(s) or licensor are credited and that the original publication in this journal is cited, in accordance with accepted academic practice. No use, distribution or reproduction is permitted which does not comply with these terms. 